\title{
A Teaching Case Using Cost/Benefit Relationships Within An ERP System
}

\author{
Joseph Ragan (Email: jragan@sju.edu), Saint Joseph’s University \\ Matthew Gantner, (Email: mgantner@sju.edu), Saint Joseph’s University \\ Patrick Caffrey, Saint Joseph’s University \\ Michael Schultz, Saint Joseph's University
}

\begin{abstract}
This paper describes a simulation model specifically for the Managerial Accounting Information Systems course - an SAP enabled course for junior Accounting majors. Supporting and measuring the Supply Chain through technology is a key goal of Accounting and should therefore be reflected in an Accounting curriculum. It will assist students to learn both the benefits, and costs, involved with implementing ERP software. The purpose of this case is to present students with a set of business scenarios, and have the students make a knowledgeable decision using SAP R/3 software. The scenarios will act as a simplified replication of the business environment; thus, they will provide the students with an integrated learning experience. They will make business decisions to ensure the profitability cash flow of their respective product lines. While making these decisions, students participate in the application and analysis provided by IDES. IDES is a simulated company within SAP for demonstration and education purposes. Eventually, the students will need to justify the existence of their division by evaluating benefits of the system verses its costs. The model created further examines the cost/benefit relationship that is undertaken when an enterprise chooses to switch from a legacy system to an ERP implementation. Students learn to compare the initial and recurring costs with the benefits derived through profitability and cash flow efficiencies. In their analysis students are confronted with both structured and unstructured information allowing them to measure and assess a full range of strategic and tactical implementations. To provide a "learning by doing" experience, the scenarios will be used to demonstrate the reporting functionality within IDES, the simulated company integrated into the SAP system. Today's global economy is putting a premium on the ability of students to evaluate a broad range of decisions in collaboration with adaptive supply chains. A critical component of the evolving accounting curriculum lies in the ability to extend students beyond the numbers to evaluate the effective and efficient delivery of these supply chains.
\end{abstract}

\section{INTRODUCTION}

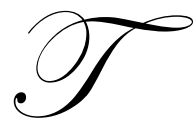

he purpose of this paper is to examine the method used to integrate the accounting curriculum with the use of SAP R/3 technology. In this paper, we will include the model of the course along with some course material.

The use of Enterprise Resource Planning systems in the business world is found in most global Fortune 500 firms which use some form of ERP with SAP and ORACLE being the leaders. Nearly $73 \%$ of Fortune 500 companies employing ERP systems use SAP. The introduction of ERP into a company's business system greatly alters the accountant's organizational duties. Automating the Accounting Information System means the accountant no longer has to perform the time consuming functions such as recording journal entries, posting these entries to ledger accounts, and preparing trial balances. Instead, the computer is able to handle these data-processing activities on a routine basis. As a result, accountants are becoming involved in the more dynamic functions of their organizations, for example aiding in management decision making and designing more effective business information systems to enable strategic analysis.

The use of ERP systems in the accounting classroom helps to show students how a simple business transaction, such as a sales order, effects the organization as a whole. By performing transactions, the students become familiar with 
the structure of the organization, the effect the transaction has on the accounting records, and the use of this information to solve problems.

\section{BACKGROUND INFORMATION}

Albrecht and Sack (2000) paint a dismal portrait of the academic accounting profession as a discipline stuck in the past and exhibiting an unwillingness to change. They observed that technological innovation has rendered the gathering and reporting of information as an inexpensive process in today's environment. Accountants must be armed, they proposed, with new skills if they are to find a role in today's environment. They suggested that accounting educators should embrace the unfolding Internet revolution and include this experience as an integral part of the pedagogy of accounting education.

Accounting professionals also recognize this revolutionary change, and promote the implementation of higher technology for business processes. The AICPA (2000b) has made internet usage one of its top ten technologies for the start of the new century. When professionals were asked what skill other than financial expertise was most critical for success in the accounting discipline, the overwhelming choice was Internet technology (AICPA, 2000a). Educational organizations, such as the Federation of Schools of Accountancy (1999), have offered strong recommendations for specific actions that might be taken by today's universities in an effort to improve technology education. Greater reliance on the Internet is one of the cornerstones of such proposals.

The overall conclusion to be drawn from recent literature geared toward technological integration is that the current level of exposure that accounting students have to Internet-related technologies is too limited. Tuteja (2000) notes that software applications - like enterprise resource planning (ERP) technologies - may generate great risk to educators in an environment of limited resources. Stedman (1999) determined that as colleges and universities adopted ERP applications for their own organizational management uses, they found a "secret resource" for use in the classroom. In customizing this type of system for classroom applications, some educational institutions seem to have found a unique way to attract students back to the classroom. Becerra-Fernandez, Murphy, and Simon (2000) note that demand for trained enterprise resource planning professionals has motivated a number of universities to join alliances with ERP software vendors such as SAP. The primary vehicle such vendors have to make their product work in the educational marketplace is through the Internet. Kaveney (2000) confirms that Internet capabilities enabled his own institution (Syracuse University) to substantially enrich both the curriculum and pedagogy in its business programs.

A particularly interesting point raised in literature deals with the role of accounting as a business integrator. George and Asha (2002) see ERP as the perfect vehicle to teach the supply chain and since SAP is a monolithic Accounting Information System it serves the effort well to demonstrate integration through accounting. Volkoff notes (2003) that teachers are currently developing cases to give a concrete sense of what it means to configure and develop ERP based software. The benefits derived provide even the accounting students with a unique appreciation for the challenge of information delivery in the future. Chau and Chan (2002) see ERP as the perfect vehicle to teach continuous process improvement and enhance project decision making. Their paper further calls for a systematic implementation process incorporating the tools from ERP into the classroom. Draijer and Schenk (2004) state that a hands-on approach will motivate students; subsequently, this will increase their understanding of the business processes. Kirby (2002) notes that, ERP has essentially overcome all the implementation problems it originally experienced, and is now the vital engine by which key information is generated for the modern business. Roby, Ross, and Boudreau (2002) reports that schools are now attempting to teach integration with the use of ERP based technologies to enhance the placement of students and build stronger core skills and consulting capabilities within their students.

The issue for study, then, is how academic accountants, the educators of future professionals, should and should not use this ERP technology to educate. The first task was choosing which version of ERP to use. SAP R/3 was chosen because it has a formal University Alliance Program, of which Saint Joseph's University is a member. As a member, Saint Joseph's University receives the full ERP suite, which constitutes twelve major modules-including forecasting, production planning, and material requirement planning areas To date, St. Joseph's University has received over $\$ 100,000$ in grants to test the implementation of SAP in the classroom. "From and educational point of view SAP's R/3 is an ideal tool to illustrate business processes and process integration" (Draijer and Schenk 2004). 


\section{SAP UNIVERSITY ALLIANCE PROGRAM}

The SAP University Alliance Program for the United States, Canada, Central and South America builds upon the best components of such a program originally developed for European institutions of higher education. It has been developed by SAP America to facilitate the use of their software package (and integrated business solutions concepts) in the formal education of undergraduate and graduate students throughout the Americas. The program has grown from a charter group of five members in 1997 to over 124 member institutions as of March 2005. The Haub School of Business is proud to be among the early schools granted admission in 1998.

Upon admission to the SAP America University Alliance Program, new members receive four significant and valuable items. First, a fully functional copy of the SAP R/3 software, or the right to time-share, with a major service provider is acquired. Second, they receive copies of all professional training materials utilized by SAP. Third, one hundred days of free training for faculty members at SAP professional training classes. The amount of training is dependent upon the level of involvement that a member institution desires. Fourth, they are given access to technical support from SAP. In addition, SAP is actively working with its member institutions to ensure cooperation and sharing of course materials among member institutions.

\section{CURRICULUM INNOVATIONS}

Pedagogical revisions to the undergraduate curriculum in Accounting at the Haub School of Business encompass two broad categories. First, a newly created three-course sequence encompassing Intermediate and Advanced Accounting has been prepared. These courses are newly titled as Financial Accounting Information Systems I, II, and III. The focus of the three-course sequence is a single continuous learning experience traversing sophomore to junior year. Each course will progressively build upon and expand the knowledge base acquired in the prior course. This knowledge base will include topical content in Accounting and application ability within SAP R/3. Second, another group of courses taught in the sophomore year incorporates subject matter inherent to cost and managerial accounting. These courses are titled Managerial Accounting Information Systems I and II. The SAP exposure afforded students within these course sequences will provide hands on experiences in a team-oriented format within a business case context. It is envisioned that a single business case will be used throughout these five courses.

\section{COLLABORATIVE LEARNING MODEL (STAR SCHOLARS)}

A unique feature of the course pedagogy is the utilization of STAR Scholars to assist in development and delivery of various SAP scenarios. These scholars are chosen through a highly selective process and specially trained to deal with these application scenarios. To date, there are some forty STAR Scholars comprised mostly of juniors and senior undergraduate majors. These students are compensated for the work done in class and are provided with enrichment activities. These activities include field visits and special speakers; the experience aims towards helping them understand the essential use of state of the art software. They often participate in research-based projects designed and developed by faculty. In addition, STAR Scholars involve themselves in a series of special activities under the direction of a Faculty mentor. Developing scenarios of various computer applications involving Enterprise Resource Planning software and SAP are included. In addition, seminars with entrepreneurs and technology leaders are held to provide opportunities to interact on a personal and informal level. Sponsored participation in special events with alumni working in technology and consulting fields is also a component. These students assist in classroom delivery and continue to service the course by maintaining a help desk for students.

\section{PHASES OF THE CURRICULUM ROLLOUT}

The courses are three-credit courses required for all accounting majors, typically in the sophomore and junior years. SJU requires all students to have laptops. A typical class consists of 24 students and is taught over a fourteen week semester. The university is a member of the SAP Alliance. As a member of the University Alliance, SJU is given access to SAP R/3 in real time (24/7) through the University of Wisconsin at Milwaukee. The objectives of the curriculum rollout were agreed upon by the department faculty in advance. 


\section{Phase I - Purchasing Phase}

The objectives established for this phase were to better understand core business processes and their linkage to accounting. The purpose of bringing SAP into the classroom further demonstrates how the roles of accountants have changed through technology. Accountants interpret business situations and use information to make decisions - they no longer simply add and subtract. It was found that using the concept of scenarios was the most ideal way to bring business situations using SAP R/3 into the classroom and have the students enter the information, master data and transactions, then see how the system uses the information, and finally use the information to make decisions for the business.

Scenarios are written in the form of scripts and tested by the STAR Scholar Team prior to their use in class. Students just follow the script to complete the process. The typical project takes them through the following steps; master file $\rightarrow$ process $\rightarrow$ report $\rightarrow$ analysis. First they create a master file, for example, a vendor master file. The students are usually asked to select a name that they will be able to identify with and remember (such as using their last name). The report would be affected by the transaction they will do in the following step. By going to the report before going through the process, students see what the number was before the transaction. After the transaction, they can see the difference the process made in the report. This enables the students to better analyze the effects of the process they went through. The last step is analyzing the process in terms of the effects it had on the business.

It was found that giving the students a script that has been written out and tested gives them a path to follow so they do not get lost in the overwhelming nature of SAP. After completing the scenario as it is written, students feel more comfortable working in the modular area in which the scenario operates. There is no such thing as an SAP expert, but there are experts in certain modules. This course was designed to make students feel comfortable when operating within the system, not to create experts.

A good way to create interest for the students is to use the email function within the system. This is done by emailing a question from our hypothetical employee, such as a $\mathrm{CEO}, \mathrm{CFO}$, etc., asking a question pertaining to the scenario performed in class. After the scenario is completed, the students respond to the question which forces them to explain the process and how it affected the business. Each student's response will contain an attached report, which will give the instructor enough information to give credit for the assignment.

It is essential for students to understand the relationship between the concept coverage within the text and the applications within SAP. A very simple overview of SAP navigation is completed in this process. The students leave with a scavenger hunt assignment using SAP navigation. Students are also introduced to the faculty website and the blackboard location for course documents and assignments. Using SAP R/3, students can now begin a walk through of the topics in the first accounting course. These topics primarily include financial statement reporting and assets. As each topic is reviewed, assignments are handed out for completion by the students, and subsequently graded. Within this first course there is an attempt to provide at least $20 \%$ of the course grade to SAP applications. It is particularly important that the students gain an appreciation of the fact that this is just the first course in which they will use SAP to enhance their study of accounting. In effect, SAP becomes the integrating factor for the entire accounting curriculum. Primary courses using SAP are financial and managerial accounting and accounting information systems. An attitude assessment conducted at this point indicates that students appreciate the more active learning approach necessitated by more hands-on computer use. In addition, students realize that the computer is doing the mechanical calculations and it is their job to manage the process flow and determine where the information is going.

\section{Phase II- Asset Reporting Phase}

The objective of this phase is to improve information system problem solving skills using performance reports. In this phase the role of technology as a cost controller is introduced to students. The major topics in a typical cost accounting course emphasize volume cost profit behavior analysis, capital budgeting (scenario demonstration provided in Appendix I), and responsibility. The scenarios written in these areas give students the opportunity to create a budget around a cost center and, as a team, measure performance and determine direction. This is done through team-based case simulations (as they now appear on the CPA exam) where students are asked to advise a client what to do regarding product cost overruns and low profitability. Student assessment surveys indicate students have a renewed appreciation on how accounting 
information affects management decision making and see the role non financial metrics play in shaping the performance and direction of the firm. Significant attention must be paid to the grading process in this phase. Students are not just graded in a normal test mode, but also are assessed points based on innovative and creative solutions communicated succinctly and efficiently to managers. A team presentation of project outcomes helps bring closure to the course and leads to conclusions that are often contingent and uncertain. This unstructured analysis often frustrates students.

\section{Phase III- Analysis Phase}

Students are provided a series of application problem scenarios where they have to provide information reports on the performance of a series of fixed assets. They must also then be able to drill down to each component to determine contribution profit and costs. Each case is graded competitively based on project presentation correct solution and clarity of information. Post surveys indicate real satisfaction with the group work and desire to make the course even more case oriented. Given the case orientation, grades tend to be higher than a normal advanced cost accounting course. The ultimate goal here is to make decisions that lead as directly as possible to benefits.

\section{EVALUATING STUDENT PERFORMANCE}

Students were asked to do a cost-benefit evaluation based on the attached Excel pro forma statement (Appendix I). The executives of IDES are in the decision making process of implementing the SAP R/3 product. They are aware of the enormous initial costs of employing such a system, and are interested in determining whether or not SAP is right for IDES.

An implementation of SAP R/3 to take two years is common. A pro forma statement is given to the students. With this pro forma statement, the expenses fall into two categories: development and operating. Development costs include every expense incurred up to the implementation date. There are five major cost involved with the development of the customized SAP R/3 system - computer time being the largest. Computer time is the composition of the man hour cost of installing the software, hardware maintenance, and the electricity required to power the systems. As a result of the higher volume of specialized computer work, it is necessary for IDES to employ a higher number of specialized personnel. This work will peak in the second year of development, and will phase out during the first years of operating SAP. The personnel fringe benefit costs are incurred in proportion of the new personnel costs. In order to successfully implement an ERP package, a specialized consulting group is usually hired to see that the implementation is as smooth as possible. In this case, IDES is commissioning a consulting firm for a total contract price of $\$ 10$ million. These fees are applied both before and after the implementation. The final cost incurred in the development phase is the record conversion expense. Data and reports from legacy systems is very valuable to management; thus it is crucial to convert the data and download it to the business warehouse feature of SAP. Unfortunately, this data conversion is expensive, but it is a one time cost. The operating costs involved with this implementation include the continuing development costs, and the addition of materials and supplies needed for systems upkeep. However, the development expenses involved have dramatically changed roles. The consultants and personnel are now focusing on continuing the functionality of SAP. Computer time (again the largest cost component) includes the electricity expense and man hours associated with computers, but software maintenance takes the place of installation.

The costs of an SAP system are very burdensome because most expenses are up front development costs, but the long-run benefits caused from personnel reductions, inventory cost reductions and improved control will greatly outweigh the costs in the long-run. Because of the MRP and production planning technology within SAP, IDES will change their inventory management technique to a Just-in-Time system. Just-in-Time will allow the production managers at IDES to order materials and have them delivered at a specified time. This will do away with most of the inventory storage and maintenance costs; the elimination of these costs is very substantial. The JIT inventory system does not require any storage facility or related equipment; this frees the assets to be sold and utilized in other ways. The other major benefit of implementation comes from the reduction of personnel. With SAP, the entering of data into the accounting system is streamlined - all departments are integrated. This eliminates the cost of employing data entry personnel, as well as their fringe benefits. The annual salary and fringe benefit costs will be carried forward in the benefit for every year following when the reduction occurred. SAP R/3 enables the user to have improved control over all aspects of the business. The reporting capabilities will increase the cash management strategy of IDES. 


\section{LESSONS LEARNED}

What does this experience suggest regarding the future of accounting education? A more holistic approach to teaching professional accountants suggests that a framework exists over a series of courses. Topics can be divided within that framework, but must use a common theme or case. In this case, the common theme was SAP and the case was cost benefit justification for implementing SAP R/3. Would other topics and themes work? Active learning with technology is a major positive and has the ability to bring outside resources and alumni into the classroom to help more advanced units.

Innovation comes at a price. The need to build incentives for faculty is particularly important. The role of the STAR Scholars can not be understated. Without their assistance, hands-on activities in class and help-desk support would not be possible. The possibility of a graduate level rollout using SAP and its more advanced modules, such as Customer Relationship Management and Strategic Enterprise Management, is under consideration. It will be the used as the topic of a follow-up study.

\section{CONCLUSION}

Students were generally receptive to the application scenarios in each of the phases. In surveying the students we found heightened interest due to the real world application of the material and the use of a leading ERP package. In balance, it was considered successful to implement in phases over a series of courses, as opposed to having one course exclusively dedicated to ERP and the R/3 System. The evidence from literature suggests that accounting education must change, and must change dramatically. Less time needs to be spent in comprehensive coverage and memorization of rules, and more time in dynamic exercises using case-based technology and the internet.

\section{REFERENCES}

1. AICPA (2000a). AICPA Core Competency Framework for Entry into the Accounting Profession, http://www.aicpa.org/edu/func.htm.

2. AICPA Top Ten Technologies Task Force (2000b). The AICPA Top Ten Technologies for 2000, http://www.toptentechs.com.

3. Albrecht, W. Steve and Robert J. Sack. Accounting Education: Charting the Course Through a Perilous Future. Sarasota, FL: American Accounting Association, 2000.

4. Becerra-Fernandez, Irma, Kenneth E. Murphy, and Steven J. Simon. Integrating ERP in the Business School Curriculum, Communications of the ACM, April 2000, pp. 39-41.

5. Draijer, Casper and Schenk, Dirk-Jan. Best Practices of Business Simulation with SAP R/3. Journal of Information Systems Education 15.3 (2004): 261-265.

6. Chau, K Y. and Chan, S. F. Implementing ERP through continuous improvement. International Journal of Manufactuing Technology and Management. Geneva: 2002. Vol. 4, Iss. 6; p. 465

7. Federation of Schools of Accountancy (1999). Recommendations for the Design of Empirical Studies Examining Curricular Efforts to Develop Student Critical Thinking Skills, http://www.thefsa.org/publications/studies.htm.

8. George, Joseph, and Asha, George. ERP, learning communities, and curriculum integration Journal of Information Systems Education, 2002, Vol. 13, Iss 1; pg. 51, 8 pgs

9. Kaveney, Michael. Syracuse University to Have New ERP Lab, Business Journal 14 (2/18/00), p. 27.

10. Kirby, Horton. ERP; A bearing on success. Works Management. Nov 2002. Vol. 55, Iss. 11; p. 8

11. Robey, Daniel, Ross, Jeanna W. and Boudreau, Marie-Claude. Learning to omplement enterprise systems: An ecploratory study of the dialectics of change. Journal of Management Information Systems. Armonk: Summer 2002. Vol. 19, Iss. 1; p. 17

12. Stedman, Craig. College ERP Success: May Take Custom Fit, Computerworld 33 (11/29/99), p. 12.

13. Tuteja, Akhilesh. Enterprise Resource Planning: It Can be Risky, May 1, 2000, http://www.itaudit.org.

14. Volkoff, Olga. Configuring an ERP system: Introducing best practices or hampering flexibility? Journal of Information Systems Education. West Lafayette: Fall 2003. Vol. 14, Iss. 3; p. 319 


\section{$\underline{\text { Appendix I }}$}

Cost/Benefit Analysis (in thousands)

Estimated Benefits (or savings):

Improved Control

Inventory Cost Reductions

Personnel Fringes Reduction

Personnel Reducations

Sale of Buildings and Equipment

Total Estimated Benefits

Estimated Development Costs:

Computer Time

Consultant Fees

Personnel

Personnel Finges

Record conversions

Total Estimated Development Costs

Estimated Additional Operating Costs:

Computer Time

Consultant Fees

Materials and Supplies

Personnel

Personnel Fringes

Total Estimated Operating Costs

Total Costs

Net Savings (Loss)

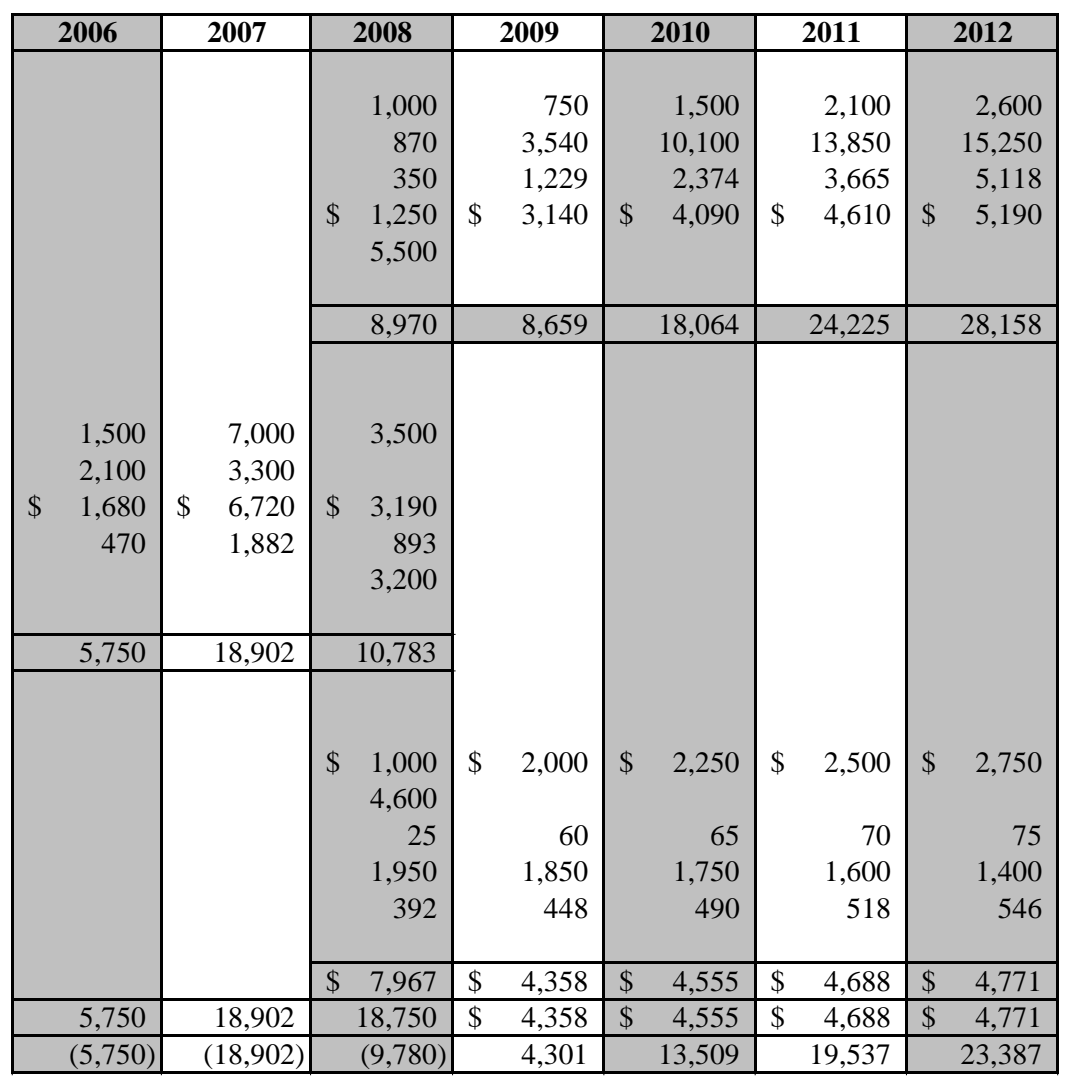

Total Savings

88,077

Total Costs

61,774

Discount Rate

$12 \%$

NPV

$\$ 3,712.63$

IRR

$15.80 \%$ 


\section{NOTES}

